\title{
The impact of substance abuse
}

\author{
Joseph A Califano Jr
}

The new Democrats and the Newt Republicans want to reform welfare, reduce crime, cut taxes, reshape Medicare, increase worker productivity and international competitiveness, house the homeless, and free state and federal budgets from the shackles of prison and Medicaid costs. The greatest obstacle to this proposed reinvention of America is abuse and addiction involving all substances: tobacco, alcohol, pills, and drugs. American leaders can soft-pedal the gravity of the addiction epidemic because so many individuals are content with their own self-denial. Yet, it is hard to find an American whom substance abuse has not touched directly.

The anecdotal evidence is everywhere, even among society's most successful members; in the addiction to alcohol and pills of megastars like Elizabeth Taylor and Liza Minelli, in the death of Maryland college basketball star Len Bias from a cocaine overdose just as he was about to embark on a promising professional career, in the destructive cocaine and heroin dependence of Eugene Fodor, the first American to share top honours at the Tchaikovsky violin competition in Moscow, in the life threatening alcohol and drug addiction of Robin Williams, and the overdose death of Williams' friend, John Belushi, in Cy Young Award winner Dwight Gooden's cocaine abuse, and addiction-plagued pro football stars like Dexter Manley and Lawrence Taylor, and in the death of rock star Kurt Cobain.

Those who work the halls of national and state legislatures know how treacherous the lure of alcohol and pills can be in the corridors of political success. We have seen this in the political wives Kitty Dukakis and Betty Ford, and in the long line of alcohol abusing politicians, including at the peaks of their careers two of the most powerful congressional committee chairmen ever, Wilbur Mills and Russell Long.

And is there an American without a family member or friend who smoked themselves to premature disability or death from emphysema, lung cancer, or heart disease? The celebrity morbidity list here begins with Humphrey Bogart and Nat King Cole, and gets longer each day, just a couple of years ago claiming pop singer and two-pack-a-day smoker Mary Wells and Pat Nixon as cancer victims.

The statistical evidence gives substance abuse and addiction its sinister status as Public Health Enemy Number One. More than 50 million Americans are hooked on cigarettes, about 18 million are alcoholics or alcohol abusers, more than five million smoke marijuana at least once a week, two million snort cocaine, including half a million addicted to crack. As many as a million are hooked on heroin, eight million abuse psychotherapeutic drugs like tranquillizers, amphetamines, and sleeping pills. Up to a million regularly use hallucinogens like LSD and PCP, and some one million Americans, half of them teenagers, use black market steroids.

If illegal drug use is falling among affluent teenagers, binge drinking is still common among high school seniors and college students, and from 1977 to 1993, the percentage of college women who reported drinking to get drunk more than tripled from $10 \%$ to $35 \%$. Princeton University president Howard Shapiro calls alcohol abuse "the greatest single threat to the university's fulfilment of its mission". The human misery caused by addiction and abuse cannot be calculated; the broken homes, the lives snuffed out in their twenties, the teenage mothers and absent fathers, women victimised by violence and rape, babies disabled by a mother's smoking, drinking, or using drugs during pregnancy, children molested by a father hopped up on beer or marijuana or cocaine, old people locking themselves in apartments terrorised at the thought of grocery shopping even in daytime, children - yes, children committing suicide. We know that a child who smokes marijuana is twice as likely to commit suicide as one who doesn't.

Substance abuse and addiction visit a special savagery on America's poor and minorities, but they spawn tragedies far beyond the black and Hispanic ghettos of poverty. Heroin wrenched the life away from Ethel Kennedy's son, David, in a luxurious Palm Beach hotel at the age of 28 , and alcohol and drug addiction have touched many other members of that royal American family, including Robert Kennedy Jr, Matthew Kennedy, Patrick Kennedy, Joan Kennedy, Patricia Kennedy Lawford, and her son, Christopher, who chairs a special projects committee at the Center for Addiction and Substance Abuse (CASA) at Columbia University.

If we cannot repair the broken hearts, we can at least put dollar signs on some costs. This year the financial bill will hit $\$ 400$ billion in health care costs, lower productivity, disability, social welfare payments, fires, crime and punishment, and the expense of prisons, property damage from vandalism, and security 
systems to protect homes and offices. Almost one of every six of the trillion dollars we will spend on health care this year will be tribute paid to substance abuse and addiction. Half our hospital beds hold victims in auto and home accidents, cancer, heart disease, cirrhosis, kidney and respiratory illnesses, and violence, caused or exacerbated by tobacco, alcohol, and drugs. And the ripple impact on American society is becoming more apparent and frightening. Two thirds of illegal drug users work either part time or full time, and many businessmen are beginning to recognise that they can't achieve world class levels of productivity and quality without reducing substance abuse among American workers.

Addiction and abuse have changed the way we educate millions of our children and even the way we graduate them from college. In many urban centres, teachers are terrorised by drug dealers, many of them students. Those who teach find it distracting and intimidating, to say the least, to be ushered in with their students through metal detectors as they enter the school building, and for their own protection in many urban centres, to be locked in the classroom while teaching. Michael Sovern, the recent president of Columbia University, told me that a few years ago he moved the graduation ceremony at Columbia from afternoon to morning in order to minimise rampant and unruly drunkenness. Surprised, I have mentioned this to several other university presidents. Most confessed they had done the same.

Cigarettes and alcohol and drug abuse have been pushing up taxes and raiding government coffers for years. Americans crippled by smoking and alcohol abuse will take home $\$ 5.6$ billion in social security disability benefits in 1995 - not welfare, just social security disability benefits - and $\$ 4.6$ billion of that is due to cigarette smoking this year. At CASA, we have done a study of the cost of substance abuse to the Medicare programme, projected forward for 20 years. Medicare will pay $\$ 1$ trillion to treat diseases as a result of substance abuse over the next 20 years; $\$ 800$ billion of that will be due to cigarette smoking. As smoking among men has declined dramatically, smoking among women has fallen much less quickly, and women are beginning to move into that over 65 years bracket with the same smoking related diseases that men have.

Eighty per cent of state and local prison inmates are there for drug or alcohol related crimes; they are not necessarily addicts, but they were high at the time they committed the offence. Most mothers on long term welfare start with a teenage pregnancy, and there is no surer way of getting locked in poverty than becoming pregnant before you graduate from high school. Many of these pregnancies occur when one of the partners is high on booze or drugs. When the mother smokes, drinks, or uses drugs during pregnancy, the medical care to deliver her child jumps sharply. Ask your retail merchant why he left the downtown area, and he will probably respond "drugs." $\mathrm{Al}$ cohol and drug abuse have fuelled a new $\$ 65$ billion-a-year industry: security guards and devices to protect property from addicts who steal to feed their habits, and from marijuana and alcohol abusing vandals.

The abuse and addiction pandemic threatens our democratic institutions. For years, the criminal courts have been clogged with drug cases, but now the civil court system in many parts of the nation is simply not available to citizens angry enough to sue. So many judges have been diverted to criminal drug case duty that civil suits in many states languish for years, effectively denying plaintiffs any relief. In most parts of New Jersey, even family divorce cases and separation cases take three years to come to trial, leaving the spouses and the children in the nasty limbo of uncertainty.

America's children are greatly at risk: from cigarette companies with their Joe Camel campaigns, to beer and alcohol advertisers who are the source of one third of all college newspaper revenue, to drug dealers who involve poor children in the drug trade and push drugs on teenagers and subteenagers. Most everyone addicted to nicotine and hard drugs is hooked before they are 21 . The younger an individual becomes a smoker and regular drinker, the more likely he or she is to get hooked on alcohol or drugs. Half a million children in our country are in foster care, double the number of five years ago, an increase largely attributable to crack. Alcohol and drugs are the prime culprits in the spread of AIDS. Intravenous drug use is the conventional culprit, but abuse of beer, liquor, marijuana, and cocaine plays a role because young Americans, high on such substances, are far more likely to have sex and to have it without a condom. Every three years, substance abuse and addiction claims almost two million Americans, most of them cigarette smokers, more people than have died in all our wars and all our automobile accidents combined.

What can we do? First, we can end the denial, face the facts honestly and blow away the politically convenient myths. Most of our public energy and resources have been spent waging a limited war to keep illegal drugs out of the country. That war is important, but it has proved quixotic and too narrow minded. The root of the problem is not in faraway places like Turkey's poppy fields, Southeast Asia's golden triangle, or South America's jungles, but within ourselves. Drugs are not invaders, but invitees to the homes and neighbourhoods of America. We are $5 \%$ of the world's population. We consume almost $50 \%$ of the world's illegal drugs. Most public policies guiding the nation's various wars on drugs have fallen short. Yet one political leader after another orders up more of the same, more policemen, more prisons, more tough sentences. Let us recognise these leaders, Republican and Democrat alike, for what they are. They are a chorus of politicians pounding the table hard, and shouting louder and louder. If all the king's horses and all the king's men can't put Humpty Dumpty back together again, then give us more horses and give us more men. 
Second, we have got to recognise that substance abuse is a problem for all Americans, not just the poor and inner city ghettos and pockets of rural poverty. At least as many middle class affluent white youngsters experiment with drugs as do poor inner city black and Hispanic children. However, poor minority teenagers are more likely to stay the course long enough to get hooked. The middle class and affluent have more reliable support systems, families, economic security, and better schools and counselling, and they know how to tap these resources. The tenacity of alcohol and drug addiction increases as personal, social, financial, economic, and legal difficulties multiply, as they do for the poor.

Third, we have got to recognise that addiction is a chronic disease. In a medical treatment sense, addiction is more like diabetes and high blood pressure than like a broken arm or pneumonia, which can be fixed or cured in one round of treatment. Continuing care is as critical to treat the alcohol or drug addict, and perhaps the cigarette smoker, as taking insulin or antihypertension drugs is to the diabetic patient or the victim of high blood pressure.

Fourth, we have to shed our drug of the month mentality and recognise that there are very few abusers of just one substance. The enemy is substance abuse and addiction, not simply illegal drug addiction. Most alcoholics also use tranquillisers, sleeping pills, or other psychotropic drugs. For the very young, cigarettes and beer can be drugs of entry into a more dangerous world. Most cocaine and heroin addicts started on alcohol and marijuana, and continue on alcohol and marijuana A 12 to 17 year old who smokes marijuana is 85 times more likely to use cocaine, based on the national household survey of drug abuse, conducted by the National Institute on Drug Abuse, than one who doesn't. An adult who smoked as a child is three times more likely, who drank as a child is six times more likely, and who used marijuana as a child is 17 times more likely to use cocaine regularly than an adult who never used these substances as a child.

Ricocheting from drug to drug, without recognising the central problem of addiction, is the stuff of frenzy, not national policy. Alcohol topped the list of abused substances in the early sixties. By the end of the decade, marijuana was the most abused drug on college campuses, with a hefty dose of hallucinogens like LSD and PCP thrown in. In the 1970s, heroin turned our city streets into alleys of terror. A report I prepared in 1980 and 1981 on drug and alcohol abuse for the governor of New York is most notable because it hardly mentioned cocaine. That drug became the fashion of the well-to-do, and then the bane of the poor, in the mid-1980s. At the end of that decade, crack brought Wild West shootouts to urban streets. Today, heroin is returning as is the highly dangerous and addictive mixture of cocaine and heroin, and the drug of choice on America's college campuses is once again alcohol.

Fifth, we can mount a united and system- wide effort to deal with all aspects of substance abuse in America: research and practice, demand and supply, prevention and treatment. All the various wars on drugs have been subverted by fragmentation among professional disciplines, among federal, state, and local governments, and agencies within each level of government, among policy makers, researchers, and service providers, and among physicians, treatment counsellors, and social workers who often fail to work together in treating patients. Prosecutors, when they exercise their discretion, rarely consult public health officials to get the maximum public health impact from the indictments they issue. Biomedical researchers disdain behavioural scientists, keeping their distance, discouraging joint efforts, rarely sharing information and experience about tobacco, alcohol, and drug addiction. America will spend this year, at $\mathrm{NIH}$, more than $\$ 4$ billion to support basic research on cancer, cardiovascular disease, and AIDS. We shall spend less than $15 \%$ of that amount for basic research on substance abuse and addiction, the largest single cause and exacerbator of all three of those deadly ailments.

The national government, in my judgment, should invest at least a billion dollars a year in research to identify the most cost-effective treatments for those who are hooked on tobacco, alcohol, or other drugs, and to find the most persuasive causes of prevention for those who are not. With that level of consistent investment, we can attract our best minds to the antiabuse and addiction effort. It is no accident that we have such phenomenally intelligent doctors researching cancer and heart disease. Two presidents, Lyndon Johnson and Richard Nixon, in consecutive terms in office, said we would provide at least one billion dollars a year through NIH for research in this area; that is what drew so many of our great medical minds into those areas. They knew the resources would be there year after year if they decided to devote their lives to dealing with such intractable diseases. Stigma is another serious problem here. If a disease like cancer or diabetes afflicted as many Americans as tobacco, alcohol, and drug abuse and addiction do, this nation would mount a research effort on the scale of the Manhattan project to deal with it.

The lack of knowledge and scepticism about the efficacy of treatment programmes has helped convince Congress in recent years to appropriate even less money for treatment than Ronald Reagan, George Bush, or Bill Clinton had requested. Treatment works, but the only sure way not to get addicted is to stay away from drugs. We devote remarkably paltry resources to preventing our young from smoking, taking drugs, or drinking. At least among adults, America has moved from a society in which the smoker asks, "Would you like a cigarette?" to one in which the smoker sheepishly whispers, "Do you mind if I smoke?". There is also a major role for research here, particularly to discover more about how to influence the behaviour of 
teenagers, for it is in the limbo of life between childhood and adulthood that individuals are most vulnerable to smoking, drinking, and drug abuse. We know that if an individual gets through the years from 10 to 20 without smoking, abusing alcohol, and using drugs, that individual is virtually certain never to do so in the future.

Sixth, we must place the responsibility of ridding the nation of substance abuse on all institutions. Each of us, as individuals in institutions, can do much more than we do at present to combat substance abuse. What little we know about this subject begins with two propositions: it can be prevented, and the earlier abuse or addiction is spotted, the more likely it can be ended. Parents particularly must be alert to signs of drug abuse in their children, and they must be willing to act promptly and aggressively when they suspect that a child has a problem. Each professional and institutional system, and those who work in them, should assume more responsibility to insist on smoke-free environments and to spot substance abuse and know how to act when it is spotted.

Seventh, we can take advantage of the captive audiences. Teachers in the classroom should learn how to detect substance abuse in children and parents and what the counselling and treatment options are. Physicians can identify substance abuse in patients, but they rarely take the responsibility of doing so. Ophthalmologists can spot drug and alcohol abuse during any routine eye examination. Dermatologists can spot smokers but they rarely do anything about it. Nurses could be particularly effective in emergency rooms. Most emergency visits - true emergencies involve injuries or heart attacks in which cigarettes, alcohol, or drugs are implicated.

And nowhere is our failure to take advantage of captive audiences more costly than in the nation's prison system. We broke the one million prisoners a year barrier in this country last year, and on the trajectory we are on, we will have more than two million prisoners in this country just beyond the year 2000. Eighty percent of the individuals in state and local prisons are there for drug or alcohol related crimes. Sixty percent of the individuals in federal prisons are there for violating the drug laws. Eighty percent of the people in prison have previously been convicted of a felony. We do virtually nothing to treat these individuals while they are in prison. In my judgment, instead of the mandatory sentences we have, we could provide treatment for anyone who is addicted to drugs or alcohol while they are in prison, and the mandatory sentence would be that they demonstrate a year's sobriety before release.

Eighth, we can move the issues of substance abuse into the mainstream of America's medical, social, economic, and political discourse, and accord work in the field the same respect and panache that we accord other professions. It should be as fashionable to search for a cure to addiction as it is to look for a vaccine for polio or seek a cure for multiple sclerosis. Parents should be as proud to say my son or my daughter, the addiction counsellor, as they are to say my son, the oncologist, or my daughter, the cardiologist. Family members should feel free to discuss a relative's drug or alcohol problem, just the way they discuss the results of it, the cancer or heart disease.

In his epic $A$ Study of History, Arnold Toynbee concluded that the great civilisations were destroyed by self inflicted wounds; not by enemies without, but within. As Toynbee put it, in all 16 cases reviewed, the most that an alien enemy has achieved has been to give an expiring suicide her coup de grace. The threat of destruction from substance abuse is not the only internal threat our nation faces, but it is the most pernicious and costly. The human nature of Americans is no different than that of the Greeks whose affluence ultimately led them to a decadent society, the Romans who came to believe that a people drenched in self indulgence did not endanger their empire, or the Chinese whose civilisation was destroyed by the widespread availability and use of opium. Americans are no more immune from the laws of history than those great civilisations were. It doesn't take a Cassandra to see the fault lines within our own civilisation. The last 25 years have given us plenty of warning signals, but no sirens screech more insistently than these: the disintegration of the family, the decline of American education and child health, and the relentless plague of tobacco, alcohol, and drug abuse.

The most ominous dimension of these forces is that they goad each other, and that each has its sinister sights fixed on the same vulnerable and precious targets: our children and our teenagers, and that alone offers sufficient reason to act now on substance addiction and abuse.

\section{Questions and answers}

ELLEN R GRITZ: What I would like to ask you to address is the political and economic realities behind your charge to this audience, given the tremendous power that the tobacco industry continues to wield?
JOSEPH A CALIFANO: There are political realities. The industry has more money than we will ever have. But I think we have tremendous opportunities with the media, particularly with respect to television, both 
local and national, bolstered by the fact that the industry cannot advertise cigarettes on television. It is a key reason why television reporters are so good at covering this subject, and we ought to try and get them to cover it more.

We do two things at the Center on Addiction and Substance Abuse at Columbia University (CASA). We run demonstration programmes, and we do studies designed to illuminate these problems and help inform our people. We are going system by system. We have almost finished an analysis of the cost of substance abuse to the health care system. We have done inpatient Medicaid hospital costs, some of which I mentioned. We have done inpatient Medicare hospital costs. By the middle of this year, we shall be releasing a report on the cost of tobacco, drugs, and alcohol to the health care system.

We have begun an analysis of the costs to the legal system, and we have just developed a protocol for the costs to business, and after that we will go after education. We have to demonstrate these relationships.

JOHN R HUGHES: CASA has done an excellent job of taking scientific information to raise consciousness and awareness about drug abuse problems, but I would suggest that we, in this audience, face the same problem with our friends working on substance abuse problems.

We know that tobacco accounts for $60-80 \%$ of substance abuse problems. I would be satisfied when CASA and the National Institute on Drug Abuse (NIDA) spend $80 \%$ of their time on tobacco-related illnesses. So the same sort of problems that you face with the general public, making them aware of substance abuse, we face with the substance abuse community, trying to make them aware that tobacco accounts for $80 \%$ of the substance abuse problems.

JOSEPH A CALIFANO: I agree with your assessment of the challenge, and I think you will see a focus on tobacco use in our Medicare study and in our health care study. Our recent commission on substance abuse in colleges and universities ended up focusing primarily on alcohol because that is where they saw the large problem. We have just established a commission to look at substance abuse among high school students, and I am sure tobacco will play a major role in their report.

DAVID B ABRAMS: Despite the failure of the Clinton health care reform package, I think we were already seeing at the tail end of it that the fuller prevention packages were probably not going to make it into the final managed care priorities.

I wonder if there are any lessons and insights to be learned from that, because managed care is clearly here to stay, and is going ahead despite government intervention. How can we raise the sort of level or the incentives to get for health promotion and prevention more than a window dressing place in managed care?
JOSEPH A CALIFANO: This is not particularly popular in this day and age, but I think with the reality of the pressures on managed care organisations to produce health care treatment at the lowest possible cost, the only way in the next few years we are going to deal with that is to have legislation that requires managed care organisations to commit some amount of their resources to prevention, and certainly to provide substance abuse treatment.

It is also important to emphasise health promotion. We have a lot of incentives we can put in the system. Health insurance should cost more for smokers than non-smokers, for example. I think there is a variety of things we can do, but we need a legal requirement to make it happen, given the pressure on managed care organisations.

RONALD M DAVIS: Mr Califano, when you were Secretary of Health, Education, and Welfare (HEW) and were launching your antitobacco campaign, many people in the White House were concerned about the impact on President Carter's political future.

It seems that right now we have a similar situation, with the FDA and the Occupationa Health and Safety Administration (OSHA) poised to announce very aggressive antitobacco regulations. We probably have people in the White House who would just as soon have the executive branch back off on tobacco, and perhaps not cost President Clinton support in the southeastern part of the country for the next presidential campaign. Based on your own personal experience, how do we combat this political problem?

JOSEPH A CALIFANO: I think the problem is probably more of money than of votes. It would be extraordinary for President Clinton to carry any southern states besides Arkansas, so he is not going to lose something he otherwise might have had.

But money is very, very important. I think the politics of tobacco at the national level are driven by money. You remind me of an experience in the early 1980s. Mayor Ed Koch asked me if I would chair a commission on smoke-free space and draft a law for New York City. We drafted a law, which is the same law that has been toughened recently, and the tobacco industry indicated they were going to spend $\$ 5$ million to kill the law in the city council. I was speaking to Mayor Koch about this, and I said, "All this work is really for naught, we are dead, I have been through this before." But he replied, "You don't understand, this is New York." I asked what he meant, and he explained that the city council will take the $\$ 5$ million, then they will vote for the law, which they did. Unfortunately, the national legislature does not operate in that way.

BRUCE K LIESE: In some ways I am disappointed that you are not going to speak later, because I am curious about your thoughts on harm reduction. I was in agree- 
ment with your book regarding not legalising illicit drugs, and was interested in what your thoughts are about needle exchange programmes and other harm reduction methods.

JOSEPH A CALIFANO: I think legalisation of drugs would be a terrible mistake for a variety of reasons. It has not worked wherever it has been tried, to the extent it has been tried. I do not know if any of you saw the $A B C$ special on addiction last Thursday night, but I was personally appalled by that. They presented smoking pot in The Netherlands where anybody over 16 can buy pot freely, and they put a couple of people on to rhapsodise about legalised marijuana. They never mentioned that the number of young marijuana users in The Netherlands has gone up $250 \%$ over the last decade, that the rate of crime, particularly property crimes, has soared in The Netherlands, and that Amsterdam has twice as many police officers relative to its population as the average American city. They have a number of serious problems there. In England, they presented a doctor who said that there were 400 individuals on heroin maintenance, and then produced anecdotal studies indicating that the drug dealers were leaving the streets. They never mentioned that there are 150000 heroin addicts in England, and I hardly think having 400 on heroin maintenance has put any drug dealer out of business.

And they never cited the other experiences in Europe. Italy has decriminalised heroin since 1975 and has 300000 heroin addicts, the highest proportionate number in Europe. Sweden tried prescribing drugs in 1965; they then stopped because of what happened. In 1980 , Sweden moved to policies just like ours, declaring the objective of a drug-free country, and they have had a sharp fall in the number of military conscripts using drugs $(75 \%)$, and in the number of ninth graders-a reduction of $66 \%$ since they moved to that policy. They didn't mention Needle Park in Zurich. It was started for a few hundred addicts. Within a few years, there were 20000 heroin addicts in and around Needle Park. The Swiss cleaned it out. They moved it to an abandoned railway yard, and in February of this year, they had to clean that out too. They have now adopted fairly tough policies.

I shall make one other point about legalisation. We have had no success in keeping cigarettes or alcohol out of the hands of children. If there is an indictment against the cigarette industry in this country, it is that they probably do more damage to America's chil- dren than anyone else. They are murderers' row for our children in this country, and it is a disgrace. We have three million children in this country who smoke under age, and we have millions of underage children who drink. I do not see any reason for greater success with drugs if they became legal.

On needle exchanges, I think we do not know yet how well they work. Some people say they work, some people say they don't. In the context of HIV, we ought to be looking at exchanges and systematically analysing, but I think the jury is out.

STEPHEN I RENNARD: Addiction as a whole seems to be increasing as a problem for America. While our goals have not been met with smoking, there certainly has been some success in reducing the number of smokers. Can you explain the apparent decrease in smoking prevalence while there is an increase in other kinds of addictive behaviour?

JOSEPH A CALIFANO: Let me make something clear. We have had remarkable success in this country in reducing the use of experimental drugs, and it is by experimentation that you ultimately become hooked. Nobody who snorts their first cocaine or smokes their first joint thinks they are going to get hooked.

We have had a $50 \%$ reduction in drug use in this country. On the "Nightline" programme recently, Ted Koppel pointed out the sharp reductions in cocaine use among the general population and in marijuana use among young people. There has been a small increase in the last year or two, but I think this is because the consistent messages of recent years have become mixed, partly by the Surgeon General, partly by the revival of pot as a big part of our popular music and in the movies. We have had some increase in smoking as well, I think partly because there is so much smoking in movies and because of the contemporary culture among our young people.

The two things I wish I had known in my years at HEW in the way that I know them now are first the relation between weight and quitting smoking as far as young women are concerned, and what a tremendous motivation that was to keep women smoking; and second, I did not really appreciate how critical those years from 10 to 20 were for every aspect of what the government does in terms of research and prevention. If we get people through those teenage years without smoking or without using drugs, they are home and dry. 